\title{
Optimalisasi Pemanfaatan Lahan Pekarangan Untuk Pemenuhan Kebutuhan Sayuran Yang Sehat Dan Aman
}

\author{
Sarjiyah*, Eni Istiyanti \\ Prodi Agroteknologi, Fakultas Pertanian, Universitas Muhammadiyah Yogyakarta, Jl. Brawijaya, Kasihan, Bantul, Yogyakarta \\ *Email : sarjiyah@umy.ac.id \\ DOI: $10.18196 / p p m .32 .221$
}

\begin{abstract}
Abstrak
Program nasional gerakan menanam tanaman di lahan pekarangan dalam rangka mewujudkan ketahanan pangan, kemandirian pangan, dan kedaulatan pangan sudah dicanangkan sejak 2015 sampai sekarang melalui kegiatan pekarangan pangan lestari dan pertanian keluarga. Lahan pekarangan warga Aisyiyah Ngestiharjo dan Tamantirto belum dimanfaatkan secara optimal. Lahan pekarangan lebih banyak digunakan untuk fasilitas umum. Tanaman dipandang kurang bernilai ekonomi. Pengetahuan dan wawasan anggota Aisyiyah masih terbatas dan keterampilan anggota Aisyiyah dalam budi daya tanaman masih rendah. Solusinya adalah memanfaatan pekarangan secara optimal melalui penerapan teknologi budi daya tanaman yang produktif, misalnya vertikultur, hidroponik, dan bertanam sayuran dalam pot/polibag. Berdasarkan pada permasalahan dan alternatif solusi yang ditawarkan, tujuan program ini adalah meningkatkan wawasan dan keterampilan ibu-ibu anggota Aisyiyah Ranting Ngestiharjo dan Tamantirto dalam mengelola lahan pekarangan. Target luarannya adalah produk berupa berbagai jenis sayuran organik. Untuk mencapai target luaran sesuai permasalahan yang dihadapi, digunakan beberapa metode, yakni penyuluhan, pelatihan, praktik, dan pendampingan teknik penanaman sayuran dengan vertikultur, hidroponik dan pot/polibag, serta monitoring evaluasi. Hasil pelaksanaan PPM-Muh di Ranting Aisyiyah Ngestiharjo dan Tamantirto dapat menyediakan kebutuhan sayuran yang sehat dan aman untuk konsumsi keluarga, di antaranya sawi, kangkung, bayam, seledri, selada, tomat, terong, cabai buncis, dan kacang panjang.
\end{abstract}

Kata kunci ; kemandirian pangan, sayuran sehat, aman

\section{Pendahuluan}

Pangan merupakan kebutuhan vital bagi manusia. Konsumsi makanan dan minuman yang cukup akan menjadi sumber pemenuhan energi dan gizi bagi tubuh manusia. Makanan dan minuman yang akan dikonsumsi harus mengikuti standar pangan yang sehat, aman, dan bergizi. Dalam Undang-Undang Republik Indonesia Nomor 7 tahun 1996 tentang Pangan dijelaskan bahwa pemerintah bersama masyarakat bertanggung jawab untuk mewujudkan ketahanan pangan. Menurut Peraturan Pemerintah Republik Indonesia Nomor 68 tahun 2002 tentang Ketahanan Pangan, masyarakat memiliki kesempatan untuk berperan seluas-luasnya dalam mewujudkan ketahanan pangan melalui pelaksanaan produksi, perdagangan dan distribusi, penyelenggaraan cadangan pangan masyarakat, serta pencegahan dan penanggulangan masalah pangan.

Program nasional gerakan menanam tanaman di pekarangan rumah dalam rangka mewujudkan ketahanan pangan, kemandirian pangan, dan kedaulatan pangan sudah dicanangkan sejak 2015. Setiap warga rumah tangga wajib berpartisipasi dalam kegiatan tersebut (Delima Hasri Ashahari, 2013). Salah satu upaya dalam mewujudkan kemandirian pangan adalah pemanfaatan lahan pekarangan secara optimal (intensifikasi pekarangan) dengan mengusahakan tanaman pertanian, baik tanaman sayuran, buah-buahan, obat-obatan maupun 
pangan (sumber karbohidrat). Aisyiyah sebagai gerakan perempuan Muhammadiyah telah berkiprah dan memberikan kontribusi dalam usaha-usaha memajukan kehidupan umat, bangsa, dan dunia internasional. Aisyiyah mengemban misi dakwah dan tajdid dan memiliki visi gerakan yang harus diwujudkan dalam menghadapi dinamika kehidupan zaman yang bersifat kekinian menuju tercapainya masyarakat Islam yang sebenar-benarnya yang membawa rahmat bagi semesta alam. Aisyiyah dihadirkan untuk mewujudkan kehidupan perempuan berkemajuan dalam seluruh aspek kehidupan. Untuk itu, peran Aisyiyah dalam membantu penyediaan pangan secara mandiri sangat diperlukan. Aisyiyah sebagai organisasi gerakan mempunyai peran strategis dalam menggerakkan warganya untuk dapat melakukan program tersebut demi mewujudkan ketahanan pangan, kamandirian, dan kedaulatan pangan.

Kegiatan rumah tangga yang dapat dilakukan yaitu membudayakan kebiasaan menanam. Warga di pedesaan dapat dengan mudah menanam jenis pangan yang akan mereka konsumsi. Namun, warga perkotaan dengan lahan sempit dapat membudidayakan pangan, seperti buah dan sayur, dengan menanam secara vertikultur, hidroponik, polibag yang disusun rapi di halaman rumah atau lahan kosong yang belum dimanfaatkan secara optimal untuk keperluan warga setempat. Zenzen (2016); Supriyanto (2016) mengungkapkan ada beberapa jenis penanaman di lahan sempit dan dapat menghasilkan keuntungan besar yang bisa dikerjakan di rumah. Karena memanfaatkan lahan yang sempit, jenis penanaman ini tidak menguras biaya yang besar. Biasanya budi daya tanaman dalam sekala kecil lebih irit biaya dan perawatannya pun sangat mudah dijangkau. Zenzen memberikan beberapa solusi penanaman yang cocok untuk lahan yang sempit, yaitu hidroponik, pot, dalam kontainer, berkebun vertikal, kebun buah-buahan, dan bertanam di atap rumah. Penanaman tanaman sayur dan buah di lahan pekarangan mempunyai kelebihan, yaitu produk yang dihasilkan sehat dan aman karena tidak mengandung residu pestisida. Dalam budi daya tanaman di pekarangan ini, tidak digunakan pestisida sintetik yang berisiko meninggalkan residu tinggi. Karena luasan yang terbatas, pengendaian hama dan penyakit dapat dimonitor dan dikendalikan secara manual atau cara lain yang ramah lingkungan. Sementara itu, penggunaan pupuk dan pestisida sintetik pada tanaman sayuran dan buah di lahan yang luas (sawah atau kebun) dirasakan petani sangat efektif, praktis, dan mendatangkan keuntungan ekonomi yang besar bagi petani.Semakin banyak pestisida digunakan semakin baik karena produk pertanian menjadi semakin tinggi. Inilah pandangan umum yang masih berlaku di dunia sampai saat ini, termasuk juga Indonesia. Di samping segala keberhasilannya, manusia semakin merasakan dampak negatif pestisida yang sangat memprihatinkan bagi kelangsungan hidup manusia di biosfer ini. Bukti-bukti semakin berdatangan tentang banyaknya korban pestisida, baik binatang berharga, ternak, dan manusia sendiri. Residu pestisida pada makanan dan lingkungan semakin menakutkan manusia (Anonim, 1993). Penggunan bahan kimia oleh pelaku usaha yang tidak sesuai aturan dapat mengganggu, merugikan, dan membahayakan kesehatan manusia. Oleh karena itu, perlu adanya komunikasi kepada seluruh pihak terkait, baik pemerintah, akademisi, industri, maupun masyarakat. Hal ini perlu dilakukan untuk mencapai tujuan makanan yang aman, bermutu, dan bergizi di masyarakat.

Di Ranting Aisyiyah Ngestiharjo yang terletak di perbatasan Kota Yogyakarta, banyak penduduk pendatang dan bangunan rumah yang semakin padat dengan luas pekarangan semakin terbatas. Namun demikian, belum dimanfaatkan secara intensif dan perlu dioptimalkan pemanfaatannya dengan lebih produktif. Demikian pula di Ranting Aisyiyah Tamantirto yang berdekatan dengan kampus Universitas Muhammadiyah Yogyakarta, banyak pendatang dan bangunan rumah kost yang pekarangannya semakin terbatas dan belum dimanfaatkan secara optimal. Berdasarkan pada permasalahan dan alternatif solusi yang ditawarkan, tujuan program ini adalah meningkatkan wawasan dan keterampilan ibu-ibu anggota Aisyiyah dalam mengelola lahan pekarangan agar lebih produktif. Adapun target luarannya adalah produk berbagai jenis sayuran organik hasil budi daya dengan teknologi vertikultur, hidroponik, dan polybag/pot. 
Untuk mencapai target luaran sesuai permasalahan yang dihadapi, dilakukan tahapan kegiatan sebagai berikut.

\section{Sosialisasi Program dan Penyuluhan}

Kegiatan ini dilakukan dengan mengundang ibu-ibu anggota Aisyiyah untuk mengikuti penyuluhan tentang program ketahanan pangan, pengelolaan pekarangan yang produktif, pentingnya konsumsi sayuran yang sehat dan aman, serta sistem budi daya vertikultur, hidroponik, dan bertanam dalam pot/polibag.

\section{Pelatihan dan Praktek}

Pelatihan dan praktik dilakukan dengan penerapan teknologi vertikultur, hidroponik, dan polybag. Pelatihan ini juga menggunakan peralatan dan bahan yang sudah disiapkan oleh tim pelaksana program. Pelatihan dilakukan oleh tim pelaksana program, praktisi, dan pengembang hidrovertikultur dengan diikuti oleh anggota ibu-ibu anggota Aisyiyah

\section{Pendampingan}

Setelah penyuluhan, pelatihan dan demonstrasi, Ibu-Ibu anggota 'Aisyiyah melakukan praktek budi daya dengan teknologi vertikultur, hidroponik, dan bertanam dalam pot/polibag dengan dibimbing oleh Tim Pelaksana program.

Jenis sayuran yang ditanam antara lain seledri, sawi hijau (sistem vertikultur), seledri, selada, sawi sendok (sistem hidroponik), cabai, tomat, terong, kangkung (ditanam dalam pot/polibag).

\section{Monev}

Monev dilakukan secara periodik sambil melakukan pendampingan kepada ibu-ibu anggota Aisyiyah sampai berhasil melakukan praktik penerapan teknologi budi daya tanaman vertikultur, hidroponik dan bertanam dalam pot/polybag.

\section{Hasil dan Pembahasan}

\section{Koordinasi dan Konsolidasi}

Sebelum dimulai rangkaian kegiatan, untuk memperlancar pelaksanaan program, dilakukan koordinasi guna menyusun langkah strategis pelaksanaan Program Pengabdian Kemitraan Masyarakat. Koordinasi dilakukan secara internal antara Tim Pelaksana dan Tim Pendukung Pelaksana, yaitu laboran dan mahasiswa. Sementara konsolidasi dilakukan antara Tim Pelaksana dan mitra, yaitu Pimpinan Ranting Aisiyah Ngestiharjo dan Tamantirto untuk menyamakan persepsi terhadap program dan kegiatan di antara pelaksana program. Hal ini bertujuan agar setiap pelaksana memahami tahap-tahap pelaksanaan program dan indikator yang harus dicapai dari setiap program yang menjadi tanggung jawab masing-masing. Kegiatan ini dilakukan dengan mengadakan kunjungan ke lokasi dan disampaikan tentang gambaran umum kegiatan, didiskusikan pengaturan jadual kegiatan, serta observasi kondisi lingkungan pekarangan.

\section{Sosialisasi Program dan Penyuluhan}

Sebelum dilakukan sosialisasi program dan penyuluhan, untuk mengetahui sejauh mana wawasan dan pengetahuan serta pemahaman Ibu-ibu Aisyiyah terhadap pengelolaan lahan pekarangan, dilakukan pre-test. Hasil pre-test menunjukkan bahwa ibu-ibu Aisyiyah sudah mempunyai tingkat pengetahuan dan pemahaman 77,2\%.

Kegiatan sosialisasi dan penyuluhan di Ranting Aisyiyah Ngestiharjo dan Tamantirto diikuti oleh 35 orang anggota Aisyiyah sebagai penerima program (50\% dari target 60 orang, karena adanya pandemi Covid-19). Narasumber kegiatan ini adalah Tim Pelaksana dan praktisi 
yang,sudah mempunyai pengalaman dalam pengelolaan pekarangan perkotaan dengan teknologi vertikultur, hidroponik, dan pot(Gambar 1a dan 1b).

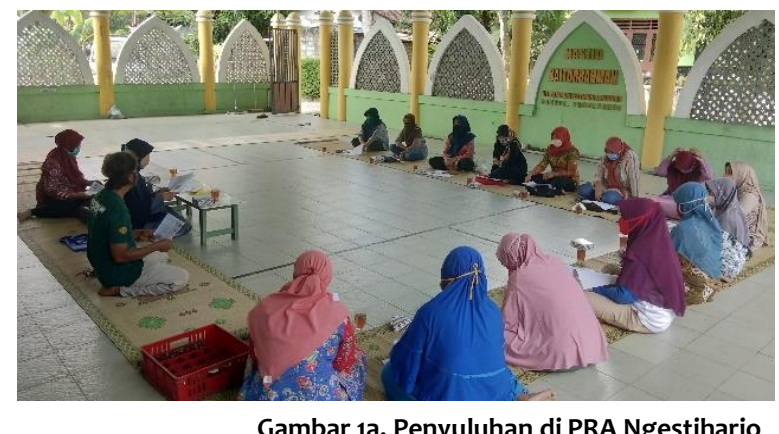

Gambar 1a. Penyuluhan di PRA Ngestiharjo

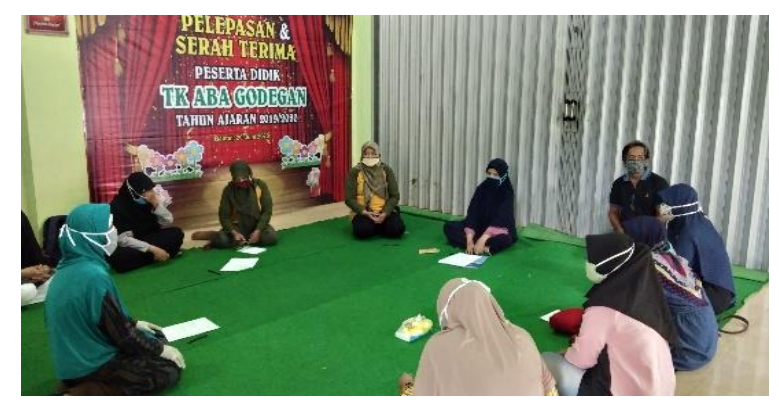

Gambar 1b. Penyuluhan di PRA Tamantirto

Materi yang disampaikan dalam penyuluhan adalah program ketahanan pangan, dan kemandirian pangan, penyediaan pangan yang sehat dan aman, pengelolaan pekarangan, teknologi budi daya tanaman secara vertikultur, hidroponik, dan tanaman dalam pot/polibag. Dalam penyuluhan, banyak tanggapan dari peserta, terutama tentang bahan untuk vertikultur, hidroponik, jenis tanaman yang dapat diusahakan di pekaranagan, pemeliharaan, dan proteksi tanaman.

\section{Pelatihan dan Praktik Penanaman Tanaman Sayuran Pelatihan Penyiapan Media Tanam}

Kegiatan pelatihan dan praktik penanaman tanaman sayuran dilakukan setelah penyuluhan dengan diawali penjelasan tentang sistem pertanaman sayuran di lahan pekarangan, instalasi alat sistem pertanaman vertikultur dan hidroponik, penyiapan alat dan bahan, penyiapan media tanam, dan penanaman. Penjelasan teknis pertanaman secara vertikultur, hidroponik, dan bertanam dalam pot dilakukan oleh Tim pelaksana dan diikuti oleh 35 anggota Aisyiyah Ranting Ngestiharjo dan Tamantirto (Gambar 2). Kegiatan ini bertujuan agar setiap anggota mitra dapat meningkatkan potensi lahan pekarangannya untuk ketersediaan pangan yang sehat dan aman bagi keluarganya dengan menggunakan teknik penanaman vertikultur, hidroponik, atau pot sesuai kondisi pekarangannya.
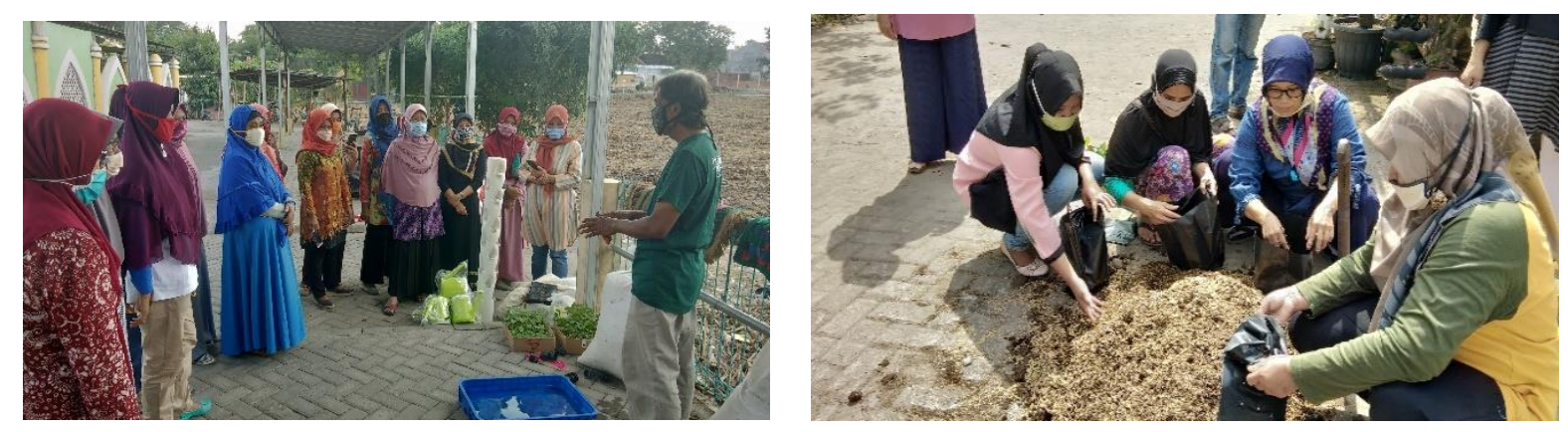

Gambar 2a. Penjelasan vertikultur, hidroponik Gambar 2b. Praktek penyiapan media tanam

Setelah pengenalan macam instalasi vertikultur dan hidroponik selesai, ibu-ibu anggota Aisyiyah dibimbing melakukan penyiapan media tanam untuk pembibitan. Penanaman sistem vertikultur dan pot/polybag terbuat dari campuran tanah, sekam padi, dan pupuk kandang dengan perbandingan 2:1:1 (Anonim, 2013). Sekam padi sebagai bahan organik digunakan untuk memperbaiki sifat fisik tanah, yaitu aerasi agar nantinya medium tanam dalam wadah tidak memadat, sedangkan pupuk kandang berfungsi untuk memperbaiki sifat fisik tanah dan sifat kimia tanah, yaitu menambah unsur hara bagi tanaman (Agus Andoko, 2014). Sementara 
sistem hidroponik menggunakan media tanam air yang dicampur dengan nutrisi tanaman (AB mix) dengan perbandingan $1 \mathrm{ml} / \mathrm{l}$ air (Untung Prasetyo, 2016).

Selanjutnya, medium tanam dimasukkan dalam bak pembibitan dan pralon tegak untuk vertikultur serta pot/polybag kemudian disiram air sampai cukup basah. Apabila media tanam memadat, ditambahkan media tanam lagi sampai penuh untuk vertikultur atau $3 / 4$ untuk pot/polybag (Gambar 3). Adapun media tanam hidroponik (air + pupuk cair) dimasukkan dalam bak plastik yang ditutup steroform dengan lubang-lubang yang diberi netpot untuk tempat menanam (Gambar 4).

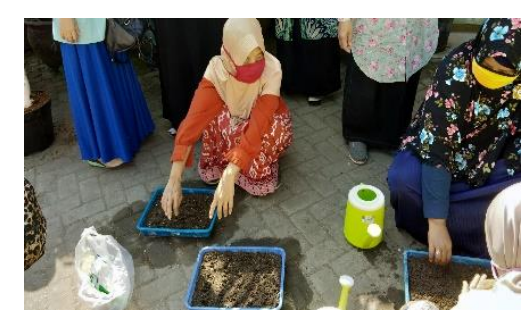

(a)

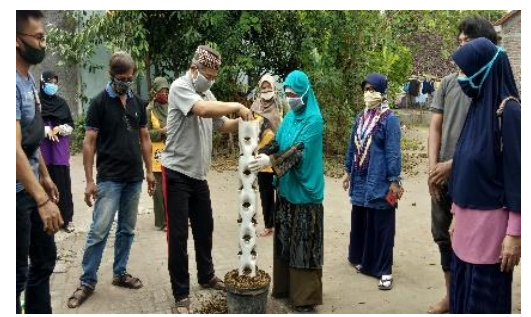

(b)

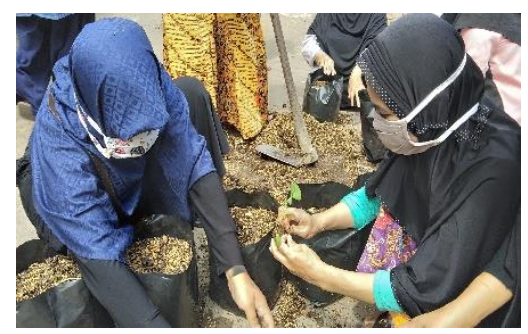

(c)

Gambar 3. Media tanam pembibitan (a), vertikultur (b) dan polybag (c)

\section{Pelatihan dan Praktek Penanaman Sayuran}

Setelah medium tanam siap digunakan untuk penanaman, ibu-ibu anggota Aisyiyah dilatih menabur benih cabai, terong, tomat, dan sawi pada bak pesemaian untuk membuat bibit tanaman sayuran. Ketika menanam bibit sawi hijau dan seledri pada media vertikultur dan menanam bibit cabai, tomat, terong dan benih kangkung pada media dalam polybag, bibit dipilih yang pertumbuhannya baik, seragam, dan tidak terkena serangan organisme pengganggu tanaman. Sebelum penanaman, polybag dibuka dengan hati-hati agar tanah yang membungkus akar tanaman tidak pecah. Selanjutnya, dibuat lubang tanam pada media tanam, kemudian bibit diletakkan di lubang tanam dan perakaran ditutup dengan tanah agar bibit dapat berdiri tegak. Agar bibit yang ditanam tidak mengalami kelayuan pada awal pertumbuhannya, setelah penanaman dilakukan penyiraman dengan air secukupnya. Sementara dalam penanaman bibit sawi hijau, selada, dan seledri pada media hidroponik (system wickpot) diperlukan pot kecil (netpot) dan spon (rockwall) untuk menanam dan menegakkan tanaman. Setelah tanaman ditanam pada spon dalam pot kecil, tanaman segera dapat menyerap air dan nutrisi tanaman yang sudah diisikan dalam bak plastik (Gambar 4).

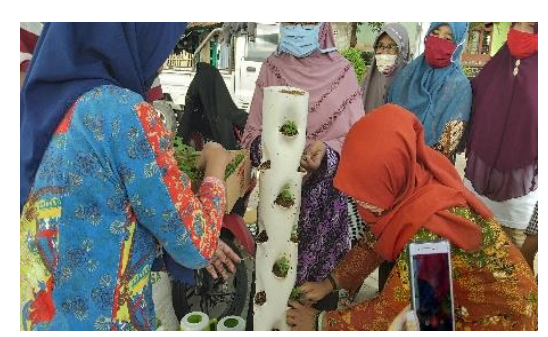

(a)

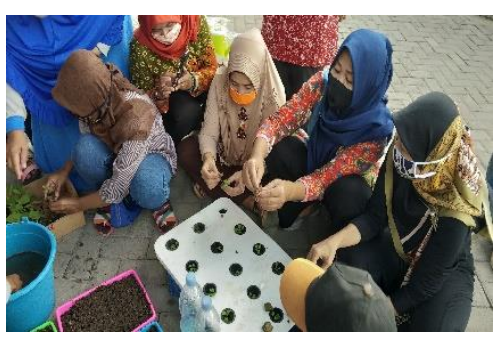

(b)

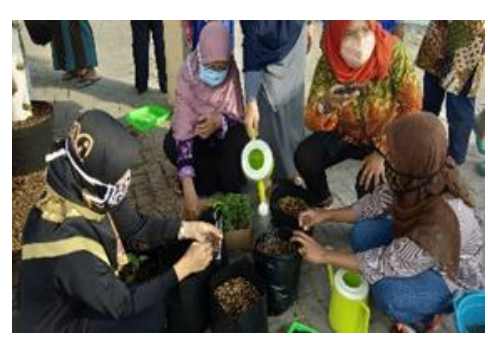

(c)

Gambar 4. Penanaman sistem Vertikultur (a), hidroponik (b) dan pot/polybag (c)

Setelah kegiatan penyuluhan, pelatihan, dan praktik penanaman tanaman sayuran selesai, dilakukan post-test untuk mengecek kembali tingkat pengetahuan dan pemahaman ibu-ibu Aisyiyah terhadap pengelolaan pekarangan. Hasil post-test menunjukkan terjadi peningkatan dari $77.2 \%$ menjadi $92,5 \%$. 


\section{Pendampingan}

Setelah mengikuti pelatihan dan praktik penanaman tanaman sayuran dengan berbagai cara dan media, diberikan bantuan sarana penanaman berupa satu set sarana penanaman hidroponik (alat, media, bibit), gembor, benih dan bibit tanaman sayuran, serta polybag untuk setiap peserta pelatihan. Selanjutnya, bantuan sarana tersebut digunakan untuk praktik penanaman sayuran di setiap rumah tangga Aisyiyah dengan didampingi tim pelaksana.

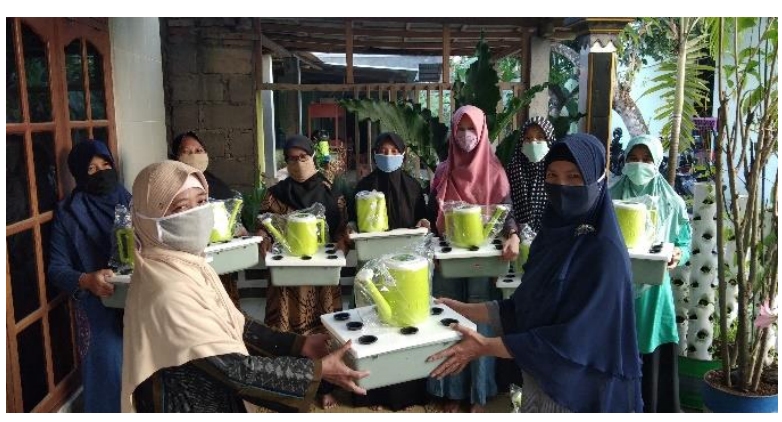

(a)

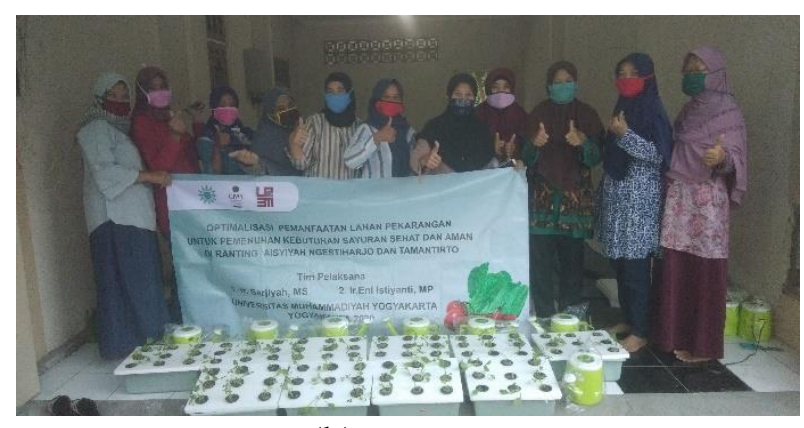

(b)

Gambar 5. Penyerahan bantuan sarana penanaman sitem hidroponik di PRA Tamantirto (a) dan PRA Ngestiharjo (b)

\section{Monitoring Evaluasi}

Kegiatan monev dilakukan secara periodik untuk mengetahui praktik pemanfaatan pekarangan untuk penanaman sayuran yang sudah dilakukan oleh ibu-ibu anggota Aisyiyah dan mengetahui kendala yang dihadapi, serta memberikan solusi. Kegiatan monev pertama dilaksanakan dengan melakukan kunjungan ke lokasi penanaman tanaman sayuran yang dilakukan oleh perorangan dan kelompok serta memberikan masukan dan arahan kepada ibu-ibu anggota Aisyiyah Ngestiharjo dan Tamantirto (Gambar 6).

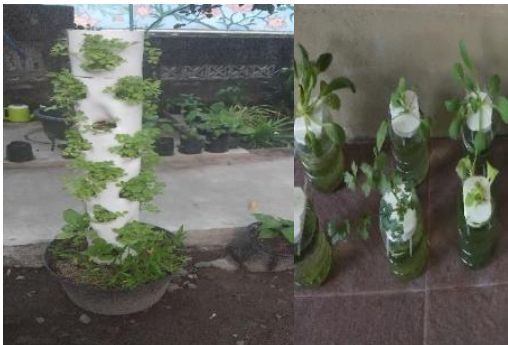

(a)

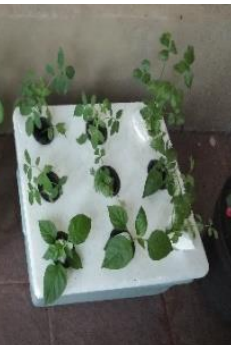

(b)

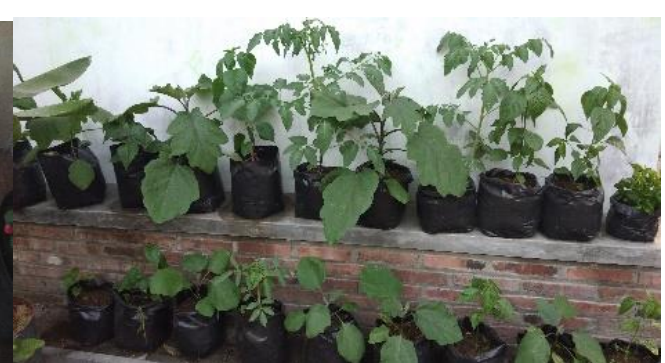

(c)

Gambar 6. Hasil praktik penanaman sistem vertikultur (a), hidroponik (b) dan polybag (c)

Kegiatan monev juga digunakan sebagai media komunikasi dan konsultasi terkait penanaman tanaman sayuran, misalnya dalam pemeliharaan tanaman seperti penyiraman, pemupukan, pengendalian hama atau penyakit, dan gulma. Penyiraman merupakan aspek yang sangat penting karena media tanam di dalam wadah terbatas volumenya. Oleh karena itu, agar tanaman dapat bertahan hidup, diperlukan kecukupan air. Untuk memenuhi kebutuhan air, media tanam disiram dengan frekuensi tergantung pada kondisi tanahdan lokasi atau tempat menanam. Pemeliharaan yang lain adalah pemupukan. Puemupukan ini dilakukan dengan menggunakan pupuk organik cair (bila diperlukan) kemudian disemprotkan atau dikocorkan pada media tanam karena produk yang diharapkan dan dihasilkan adalah sayuran organik. Proteksi tanaman dilakukan dengan cara mencabut gulma atau rumput yang tumbuh pada media tanam. Karena hama atau penyakit relatif sedikit, proteksi tanaman dilakukan secara manual, yakni dengan diambil dan dihilangkan menggunakan tangan. Pemeliharaan tanaman dengan sistem hidroponik relatif lebih mudah karena tidak perlu memupuk dan menyiram tiap hari, 
hanya perlu menambah larutan nutrisi dalam bak plastik (ember) bila debit berkurang. Hama dan penyakit relatif sedikit sehingga pengendaliannya cukup dilakukan secara manual, yakni menggunakan tangan untuk menghilangkan hama. Konsultasi dan sharing pengalaman menanam sayuran juga dilakukan oleh ibu-ibu anggota Aisyiyah melalui WA group yang sudah dibentuk setelah dilakukan pelatihan dan praktik menanam sayuran.

Monitoring dan evaluasi kedua dilakukan terhadap hasil pertanaman sayuran yang sudah ditanam oleh setiap anggota Aisyiyah atau kelompok. Pada saat monev yang ke dua ini, berbagai tanaman sayuran sudah bisa dipanen, yaitu bayam, kangkung, selada, seledri, sawi, tomat, terong, dan cabai (Gambar 7).
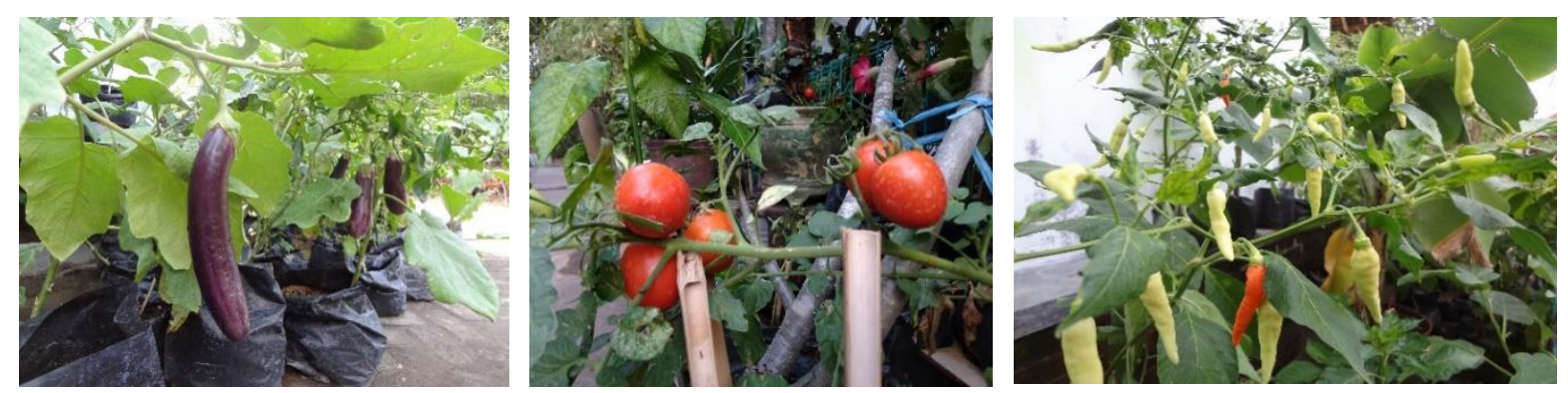

Gambar 7. Hasil panen pemanfaatan lahan pekarangan

Kendala yang dirasakan untuk keberlanjutan usaha tanaman sayuran, baik secara vertikultur, hidroponik, maupun pot di Ranting Aisyiyah Ngestiharjo dan Tamantirto adalah 1) ketersediaan bibit dan pupuk/nutrisi. Karena tanaman sayuran yang ditanam adalah tanaman semusim, setelah dipanen, tanaman harus diganti yang baru. Oleh karena itu, untuk kontinyuitas produksi/ penanaman, diperlukan bibit tanaman sayuran yang diusahakan/dikelola secara bersama-sama (kelompok), 2) umur panen tanaman sedikit lebih panjang karena keterbatasan tempat untuk pertanaman sehingga agak terlidung (kurang cahaya) dan nutrisi tanaman yang kurang karena tidak menggunakan pupuk sintetis untuk menghasilkan produk sayuran organik.

Hasil monitoring dan evaluasi yang dilakukan oleh tim pelaksana adalah bahwa sebagian ibu-ibu anggota Aisyiyah lebih tertarik penanaman tanaman sayuran menggunakan pot/polybag atau menanam langsung di tanah/lahan karena sarana tersedia, bahan mudah didapat, serta pemeliharaan mudah dilakukan setiap hari, terutama di masa pandemi karena ibu-ibu lebih banyak beraktivitas di rumah. Namun, sebagian yang lain lebih tertarik budi daya tanaman secara hidroponik karena budi daya dengan sistem ini tidak menggunakan tanah sebagai media tanam sehingga terkesan lebih bersih tempatnya dan tidak perlu memupuk dan menyiram tiap hari. Sementara ini hasil panen sayuran dikonsumsi sendiri untuk keluarga, barter antaribu-ibu anggota Aisyiyah dan disedekahkan pada tetangga. Untuk keberlanjutan usaha pemanfaatan pekarangan ini, hendaknya dibuat kelompok untuk memudahkan dalam mendapatkan sarana produksi, yaitu bibit, pupuk, dan sarana lainnya. Selain itu, pembentukan kelompok juga memudahkan penjualan hasil panen secara bersama-sama sehingga dapat menambah pendapatan keluarga.

\section{Simpulan}

PKM-M di Ranting Aisyiyah Ngestiharjo dan Tamantirto dapat meningkatkan wawasan, pengetahuan, pemahaman, dan keterampilan bu-ibu anggota Aisyiyah dalam mengelola lahan pekarangan yang lebih produktif dengan menanam berbagai tanaman sayuran dengan menggunakan teknik vertikultur, hidroponik, dan polybag sehingga dapat menyediakan kebutuhan sayuran yang sehat dan aman, di antaranya kangkung, sawi, bayam, selada, seledri, tomat, terong, cabai, buncis, dan pare. 


\section{Ucapan Terima Kasih}

Dengan telah selesainya kegiatan pengabdian pada masyarakat ini, kami mengucapkan terima kasih kepada Kepala LP3M yang telah memberikan dana pengabdian berdasarkan SK Nomor 031/PEN-LP3M/I/2020. Ucapan terima kasih juga kami sampaikan kepada Ketua PRA Ngestiharjo dan Tamantirto Utara atas segala fasilitasinya sehingga kegiatan PKM-M dapat berjalan baik, lancer, dan sukses.

\section{Daftar Pustaka}

Anonim. 1993.Prinsip-prinsip Pemahaman Pengendalian Hama Terpadu. Konsep Pengendalian Hama Terpadu.Direktorat Jenderal Tanaman Pangan dan Direktorat Bina Perlindungan Tanaman.B.I. Jakarta.

Anonim. 2013. Budidaya Tanaman Sayuran secara Vertikultur Sederhana.http://pustakapertanianub.staff.ub.ac.id/2013/01/19/budidaya-tanamansayuran-secara-vertikultur-sederhana/

Agus Andoko. 2014. Budidaya Sayuran Secara vertikultur Organik. Penebar Swadaya

Delima Hasri Ashahari. 2013. Membangun Kemandirian pangan dalam rangka meningkatkan ketahanan Nasional. Litbang Pertanian.go.id.

Supriyanto. 2016. Urban farming, menanam di lahan sempit Urban Farming https://supriliwa.wordpress.com/2016/12/05/urban-farming/Diakses 5 Januari 2020. Jam 17.50

Untung Prasetyo. 2016. Bertanam Sayuran Secara Hidroponik Pekarangan. Agromedia Pustaka.

Zenzen Zainudhin. 2016.7 Cara Agar Lahan Sempit Hasil

Melimpah.https://www.agrotani.com/7-cara-agar-lahan-sempit-hasil-melimpah/. Diakses 6 Januari 2020. 